\title{
Bringing Census Data into the Classroom: World Wide Web Access and Teacher Networking
}

by William H. Frey and Cheryl L. First ${ }^{1}$, Population

Studies Center The University of Michigan

\section{Once Upon A Time}

As Jackie, a college sophomore, puts together her fall schedule, her interest is peaked by courses which address current social issues, such as Sociology 202, which focuses on marriage and childbearing trends. Her enthusiasm for SOC 202 wanes slightly when she sees that it meets at 8:30 am. Karen, Jackie's roommate, reminds her that she needs to fulfill the statistics requirement and that STAT 402 meets at $11 \mathrm{am}$, a definite plus. Jackie groans, "That class will put me back to sleep anyway." Like many students, Jackie dreads the statistics course because her math skills are not strong. Furthermore, word on campus is that it is a dry course that has nothing to do with real life. Jackie opts for SOC 202; she will put off STAT 402 for as long as possible.

\section{From The Same Old Story To A New Perspective} Any resemblance to the living or dead in the above story is not accidental, it is inevitable. This dilemma is played out on most campuses every semester. To many, the dilemma may not seem especially problematic because "Jackie" must eventually complete the statistics requirement.

However, two major problems are created by a curriculum which presents theory and data analysis as separate entities. First, this curriculum structure leads the student to believe that the compelling questions and possible solutions to today's pressing social issues are somehow distinct from quantitative reasoning. In other words, why and how are presented, and consequently understood, as two completely different questions. The second problem is of a more practical nature, but nonetheless troublesome. When students put off the quantitative element of their degrees, they are postponing their opportunity to take the more substantive upper level courses which require data analysis skills. Consequently, the quality of their undergraduate training, and its relevance to their eventual careers, decreases.

In light of these problems, the Social Science Data Analysis Network (SSDAN) project seeks to make empirical data analysis explorations an accessible, available, and desirable component in introductory social science courses. It combines engaging course material on American society with basic data analysis exercises which utilize data from the U.S. Census and other sources. Issues that can be addressed with U.S. Census data include:

Immigration and the Increasing Diversity of the American Population

\author{
Changes in the Roles of Women and the Structure of the \\ Family
}

Industrial Restructuring and the Shrinking Middle Class

The Civil Rights Movement's Impact of Black-White Inequality

By "marrying" theory and data analysis in an active learning setting, these courses illustrate that quantitative reasoning skills are relevant to social issues. Furthermore, the courses prepare students for applied upper level courses and careers that utilize data analysis skills.

In addition to designing course material and preparing datasets, the SSDAN project provides support for instructors who are committed to, but not necessarily experienced in, incorporating "hands on" data analysis in their courses. This support includes in-person and "virtual" internet accessible workshops, a World Wide Web Homepage (See Exhibit A for SSDAN Homepage) and electronic E-mail groups. Through these mechanisms, instructors not only receive support from SSDAN staff, but also have the opportunity to network with each other. A more comprehensive explanation of these mechanisms, and other SSDAN materials, will be provided later in this paper.

The most innovative objective of this project is to introduce networking capabilities that link data and research expertise at the University of Michigan Population Studies Center with faculty at two and four year colleges. This link will enable interactive feedback on development of curricular materials over the Internet. The computer network will be used to: (1) aid in the creation of datasets and curricular (i.e. faculty will suggest exercises and relevant datasets to be produced at Michigan); and (2) to provide continuous sharing of these materials and feedback among faculty via conferencing.

\section{The Nuts and Bolts of Building A New Approach}

In order to introduce faculty to this new approach and help them create data exercises appropriate for their courses, the SSDAN project has implemented both traditional in-person workshops and a "virtual workshop" — via the Internet that enables social science faculty at two and four year colleges to exchange data and ideas through the project's World Wide Homepage and electronic E-mail groups. Through these channels, we have already developed an extensive network of over four hundred interested faculty 


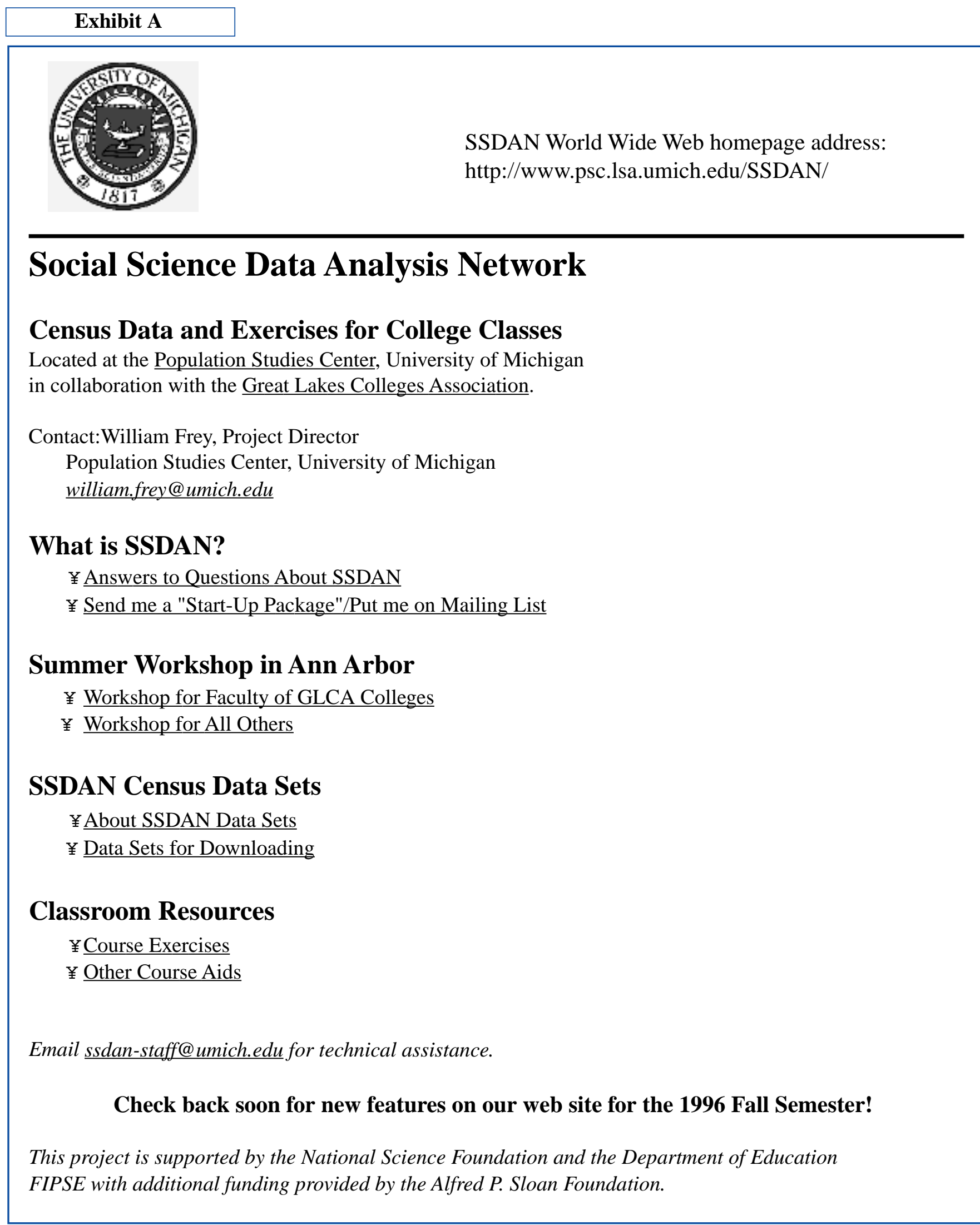


around the country. We have also published a workbook which includes over two hundred student exercises and covers ten American Society topics that can be incorporated into many social science courses. The workbook is bundled with a diskette which contains specially tailored U.S. Census data for 1950-1990 and the Chipendale program, an extremely user-friendly data analysis software for novices.

\section{In-Person Workshops}

The primary goals of the in-person workshops are: (1) To expose the participants to curricular materials we have developed through lectures, discussions, and extensive "hands-on" use; (2) to make them familiar with computer conferencing and data access features of our computer network; (3) to work with them, individually or in small teams, toward creating data analysis exercises that they will use during the next academic year; and (4) to expose participants to other resources that complement their use of the data analysis exercises they will produce in our workshop.

Our annual in-person summer workshops in Ann Arbor are open to a national audience of instructors. The two workshops, each a week long, that were held during the summer of 1996 introduced 28 college teachers to the SSDAN materials. The participants were selected from some 80 applicants, and represented a variety of colleges and social science disciplines. Primary consideration was given to highly motivated faculty interested in adding a data analysis component into a lower level substantive course they already teach. They can adapt any of the project's current census data analysis exercises to their classes or, with our assistance, develop new exercises.

Participants were introduced to the resources of SSDAN in "hands on" training sessions, had seminar discussions, worked with SSDAN staff to begin developing classroom exercises specific to their own courses, and practiced exploring the SSDAN materials. Participants were also exposed to PDQ-Explore, a "cutting edge" instructional computer tool which allows users, to conduct U.S. Census data analysis directly over the Internet. The PDQ-Explore program is currently being developed in cooperation with the University of Michigan and will be discussed later in this paper.

Overall, the workshop got high marks from the 1996 participants due to the information presented and the human networking possibilities that were set in place. We are now working with these faculty to design classroom exercise/ dataset modules that they will use. These modules and datasets will be posted on our Homepage in order to facilitate sharing among any interested instructors.

SSDAN World Wide Web Homepage : http://www.psc.lsa.umich.edu/SSDAN/ The project Homepage describes the project (See Exhibit
A), makes exercises available, and facilitates downloading of census datasets that can be accessed with Chipendale software in both IBM and MAC format. The datasets are indexed according to the variables and the kinds of courses for which the datasets are most suited. The Web page also serves to update instructors on developments related to the project, and provides links to other teaching resources. The Homepage has also been a useful way to advertise the project, and as a result, we have received requests for additional information and datasets among social science faculty in a wide variety of institutional contexts around the world. Although the Homepage is free to browsers, we do ask that they "register" with us first. The Homepage enables project participants and all others who wish to access it, with the ability to send requests and communicate with the project staff.

The project staff is currently developing more features for the web page that will assist both professors and students. Our "new and improved" homepage will include: new datasets and exercises for downloading, references to current popular and scholarly articles relevant to SSDAN; a form for faculty to submit classroom exercises and corresponding dataset ideas to SSDAN staff; and a QuickSurvey for feedback on SSDAN. In future months, we will create a section which targets students. This section, in addition to being a bit more "hip", will include links to articles which can help them with their coursework, data they may find interesting, and surveys.

\section{The "Virtual" Internet Accessible Workshop}

The most innovative aspect of this project is the implementation of a "virtual" workshop. This means that faculty from any undergraduate program can participate in the conferencing, data access, and exercise creation activities of this project by communicating with our core faculty and staff over the Internet, or using e-mail. Our "virtual" workshop revolves around two components: (1) an e-mail discussion group for active participants; and (2) a data analysis exercise "bank" that contains text and datasets for individual class exercises which can be retrieved by the instructor over the Internet or via e-mail.

To use our materials, it is not necessary that entire universities, classrooms, or student audiences have Internet access, but rather that the instructor has access, somewhere on campus, to an individual Internet connection, or e-mail account. Hence, a large body of faculty participants in this network can use this system to retrieve data exercises for use in their classes (from the "bank").

All instructors who wish the Michigan staff to work with them in producing exercises must agree to "try them out" in their own classes and provide feedback to us regarding their effectiveness. This feedback will be recorded into the notes that are attached to the data exercises, deposited in the general bank. These exercises, in addition to those created by 


\section{Exhibit B}

Example 1 Look at the percentage of blacks and nonblacks who were never married, from 1950 to 1990 . How has the percentage of each group who have never been married changed over time? What might account for these changes? (MARR5090)

n Create a line graph with separate lines for blacks and nonblacks indicating the percentage of each group who have never been married for each year.

Cross Tab= Race / Marital (control for year); Percent Across

Year $=1950$

\begin{tabular}{|c|c|c|c|c|c|c|}
\hline & CurMr & Widow & Divor & Sepra & NevMr & Total \\
\hline Black & 57.6 & 10.5 & 2.3 & 7.8 & 21.7 & $100 \%$ \\
\hline NonBl & 67.5 & 8.0 & 2.2 & 1.2 & 21.0 & $100 \%$ \\
\hline All & 66.6 & 8.2 & 2.2 & 1.9 & 21.1 & $100 \%$ \\
\hline \multicolumn{7}{|c|}{ Year $=1960$} \\
\hline & CurMr & Widow & Divor & Sepra & NevMr & Total \\
\hline Black & 56.0 & 10.0 & 3.2 & 7.7 & 23.2 & $100 \%$ \\
\hline NonBl & 68.7 & 7.8 & 2.5 & 1.2 & 19.8 & $100 \%$ \\
\hline All & 67.5 & 8.0 & 2.6 & 1.8 & 20.1 & $100 \%$ \\
\hline \multicolumn{7}{|c|}{ Year $=1970$} \\
\hline & CurMr & Widow & Divor & Sepra & NevMr & Total \\
\hline Black & 49.1 & 9.8 & 4.3 & 7.6 & 29.1 & $100 \%$ \\
\hline NonBl & 64.8 & 8.0 & 3.3 & 1.3 & 22.6 & $100 \%$ \\
\hline All & 63.2 & 8.2 & 3.4 & 1.9 & 23.3 & $100 \%$ \\
\hline \multicolumn{7}{|c|}{ Year $=1980$} \\
\hline & CurMr & Widow & Divor & Sepra & NevMr & Total \\
\hline Black & 39.4 & 8.6 & 7.7 & 7.3 & 37.0 & $100 \%$ \\
\hline NonBl & 60.2 & 7.5 & 6.0 & 1.6 & 24.6 & $100 \%$ \\
\hline All & 58.0 & 7.6 & 6.2 & 2.1 & 26.0 & $100 \%$ \\
\hline \multicolumn{7}{|c|}{ Year $=1990$} \\
\hline & CurMr & Widow & Divor & Sepra & NevMr & Total \\
\hline Black & 35.2 & 8.0 & 10.1 & 6.6 & 40.1 & $100 \%$ \\
\hline NonBl & 58.1 & 7.3 & 8.1 & 1.7 & 24.7 & $100 \%$ \\
\hline All & 55.6 & 7.4 & 8.3 & 2.3 & 26.4 & $100 \%$ \\
\hline
\end{tabular}

The answer can be plotted as follows:

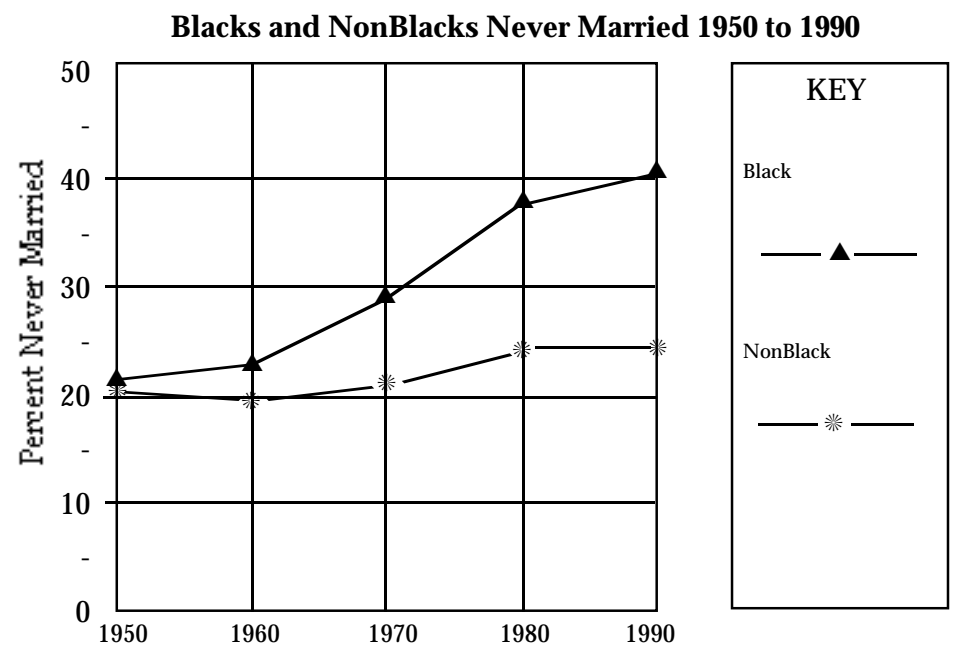


our in-person workshop members, should result in over 300 data exercises at the conclusion of the project.

\section{"Investigating Change in American Society" Workbook} Our workbook, Investigating Change in American Society: Exploring Social Trends with US Census Data and StudentChip has several Topics (chapters) that are appropriate for almost any social science course. The workbook is flexible enough to be used with a variety of texts, or additional readings, and can easily be integrated into existing courses. The single most important feature of our workbook is its adaptability to a wide range of social science courses in which the instructor wants to introduce one or more "hands on" data analysis modules. See Exhibit B for a sample exercise.

In order to make data analysis interesting and engaging to students, the workbook includes a wide variety of interesting issue-oriented topics. See Exhibit $\mathbf{C}$ below for a listing of all ten investigation topics.

These investigation topics (chapters) are self-contained. In other words, they can be "mixed and matched" according to the instructor's course sequence. Within each Topic (chapter), the difficulty level of the exercises increases as the students read through the topic. At the end of each topic there are "Think Tanks", broader questions which aim to generate class discussions. These questions are ideal for team exercises.

The students complete the data analysis modules with userfriendly, engaging Chipendale software which comes with the workbook. A full tutorial at the beginning of the book can get teachers and students "up to speed" in one classroom period.

The "look and feel" of our book is not of a statistics or methods book and our exercises are centered on having the students explore data to examine interesting and engaging social issues — rather than to learn more advanced statistical methods or jargon. This is reflected in the heavy use of graphics, and attention to understanding basic sociological concepts and measurements rather than focusing on statistical or specialized methodological concepts.

\section{The World On A Diskette}

The workbook includes a diskette (students can choose between an IBM or MAC compatible edition) containing Chipendale contingency table software. This software was selected because of the ease of use, low expense for students, and appropriateness for straightforward contingency table analyses of census data. The program is menu driven and extremely user friendly, but also sufficiently unfriendly to allow students to recognize when they have made poor decisions. The program makes it easy for students to recode variables, select controls, and make graphs that highlight their comparisons. Any standalone PC can use the software in virtually any configuration. The Chipendale program is efficient to use on any PC because it takes "input" data as tables or matrices, rather than individual cases. This allows students to manipulate large aggregate-type datasets, such as those from the U.S. Census, in small compact files.

A whole range of topics related to American social, economic and geographic issues can be explored with

\section{Exhibit B}

\section{INVESTIGATION TOPICS}

-Population Structure: Cohorts, Ages, and Change

-Race and Ethnic Inequality

-Immigrant Assimilation

-Labor Force

-Marriage, Divorce, Cohabitation, and Childbearing
-Gender Inequality

-Households and Families

-Poverty

•Children

-The Older Population 
SSDAN datasets. The datasets are drawn from the U.S. census and include variables such as: race-ethnicity, gender, immigration status, earnings, education, occupation, cohabitation, and workhours. Some allow analyses of trends over the census years 1950, 1960, 1970, 1980, and 1990.

Others permit more in-depth comparisons across social and demographic groups and geographic areas from the 1990 U.S. census.

\section{U.S. Census Data}

The most comprehensive dataset needed to assess the kinds of over-time changes that we have been discussing are available from the U.S. Census. The wide range of statistics collected by the decennial census is especially useful in social science research. This is because this information is collected for a large number of people and detailed social and economic information can be gathered for tiny population subgroups and small geographic areas. Unlike many small surveys, the census information is rarely limited by having "too few observations" to be statistically representative.

\section{SSDAN Participants}

This project especially targets groups and institutions that have often been neglected in advances of quantitative work in the social sciences. Specifically, this means concerted efforts to include women, minority and disabled faculty, as well as two-year undergraduate institutions and historically Black colleges and universities. This special targeting is made explicit in the recruiting for our in-person workshops in Ann Arbor, and in our efforts to engage off-site instructors, interactively, in creating exercises for their classes.

\section{Funding}

SSDAN is currently funded by the National Science Foundation Undergraduate Faculty Enhancement grant and a US Department of Education FIPSE Project, building upon earlier funding from the Alfred P. Sloan Foundation and an Undergraduate Initiatives Award granted to Dr. Frey who first developed this approach in his University of Michigan course. The FIPSE project demonstrated the feasibility of incorporating interactive U.S. Census data analysis via the Internet into existing undergraduate curricula in colleges of The Great Lakes Colleges Association. The current project extends this approach to a national community of social science instructors, that has come to be called SSDAN, the Social Science Data Analysis Network.

\section{The Future}

In the next year, the teaching approach of this project will be enhanced by utilizing a student version of the PDQ-Explore program and class-room exercises will be made available. As mentioned previously, the PDQ-Explore, a "cutting edge" instructional computer tool where students can conduct direct U.S. Census data analysis interactively over the Internet, is an avenue which the SSDAN will be taking.
PDQ-Explore allows users to request US Census data tables that are immediately delivered to the users computer screen over the Internet. Eventually, this program, along with the Chipendale software, will be modified so that our approach can be available to high school students, as well as undergraduate college students.

The Social Science Data Analysis Network looks forward to continuing to grow, as our network of interested faculty and our "bank" of class-room exercise modules and datasets expands. Please contact us via E-mail or through our World Wide Homepage at:

\section{http://www.psc.Isa.umich.edu/SSDAN/}

if you or one of your colleagues would like more information about the project, or would like to participate in developing exercise modules and US Census datasets for your own classroom.

1. Paper presented at the IASSIST/Computing in the Social Sciences Conference, Hotel Radisson, Minneapolis, MN, May 1995.

Dr. William H. Frey, Director of SSDAN (Social Science Data Analysis Network) is on the faculty of the Population Studies Center, and the Department of Sociology at the University of Michigan in Ann Arbor. SSDAN draws from an approach he developed with his Michigan course, and later disseminated to faculty of the Great Lakes Colleges Association.

Cheryl L. First MSW is the Project Manager of the Social Science Data Analysis Network. She coordinates the InPerson and Virtual Workshops for the project, and also maintains the SSDAN World Wide Web Homepage.

Acknowledgments: The authors are grateful to Bridget Fahrland for her editorial contributions. 